\title{
In Vitro Growth Regulation of Endometrial Carcinoma Cells by Tamoxifen and Medroxyprogesterone Acetate ${ }^{1,2}$
}

\author{
S. E. Grenman, ${ }^{* 3}$ J. A. Roberts, $†$ B. G. England, $\ddagger$ M. Grönroos,$\S$ and \\ T. E. CAREY*,4 \\ ${ }^{*}$ Cancer Research Laboratory of the Department of Otolaryngology/Head and Neck Surgery; \\ tDepartment of Obstetrics and Gynecology/Division of Gynecologic Oncology, and \\ $\ddagger$ Department of Pathology, University of Michigan, Ann Arbor, Michigan 48109; and §Department \\ of Obstetrics and Gynecology/Division of Gynecologic Oncology, University of Turku, Finland
}

Received June 1, 1987

The growth inhibitory effects of medroxyprogesterone acetate (MPA) and tamoxifen (TAM) were tested on three long-established endometrial carcinoma cell lines (HEC-1, KLE, and RL95-2) and on UM-EC-1, a new endometrial carcinoma cell line established in our laboratory. MPA and TAM were used in growth experiments either alone, simultaneously, or sequentially. The MCF-7 breast cancer cell line was used as a control. None of the endometrial carcinoma cell lines showed significant sensitivity to 0.1-10 $\mu \mathrm{M}$ MPA. In contrast, 10 days exposure to $5 \mu \mathrm{M}$ TAM induced 83 and $70 \%$ growth inhibition in HEC-1 and KLE cultures, whereas the growth of UM-EC-1 was inhibited by $99.7 \%$ and RL95-2 cultures by $100 \%$. TAM-induced growth inhibition was reversible since all cell lines resumed logarithmic growth when TAM was removed from the culture medium. Addition of $17-\beta$-estradiol $\left(\mathrm{E}_{2}\right)$ to the culture medium did not accelerate recovery, and reversal of TAM-induced growth inhibition was not seen when TAM and $E_{2}$ were added simultaneously. This is consistent with our finding that, except for MCF-7, these cell lines did not show detectable estrogen receptor (ER) activity in assays performed at the time of these experiments. When treated sequentially with TAM and MPA, all cell lines resumed logarithmic growth when medium containing TAM was replaced with medium containing MPA. Simultaneous exposure to $5 \mu M$ MPA and $5 \mu M$ TAM resulted in a slight additive growth inhibitory effects only in KLE cultures. Our results show that MPA does not have growth inhibitory effects in these endometrial carcinoma cell cultures, whereas TAM exerts a potent growth inhibitory effect that is not reversed by estrogen and may thus be mediated through a mechanism different from blockade of ER. In vitro results with the UM-EC-1 cell line correlated with the clinical response of the cell line donor. Her disease progressed

${ }^{1}$ Supported by USPHS Grant CA 28564 from the National Cancer Institute and a grant from the Finnish Cancer Society.

${ }^{2}$ Presented at the 15th Annual Meeting of the Western Association of Gynecologic Oncologists (WAGO) May 13-16, 1987, in Tucson, AZ.

${ }^{3}$ Present address: Department of Obstetrics and Gynecology at the University of Turku, Turku, Finland.

4 To whom requests for reprints should be addressed at Cancer Research Laboratory, Department of Otolaryngology/Head and Neck Surgery, 6020 KHRI, Box 0506, 1301 East Ann Street, University of Michigan, Ann Arbor, MI 48109-0506. 
during postoperative MPA therapy, but subsequently she responded to TAM therapy. (C) 1988 Academic Press, Inc.

\section{INTRODUCTION}

Medroxyprogesterone acetate (MPA) is one of the most commonly used hormonal agents for the treatment of advanced or recurrent endometrial adenocarcinoma, with a response rate of 30 to $35 \%[1,2]$. Of the progesterone receptor (PgR)positive tumors, $82-83 \%$ have been reported to respond to MPA therapy both in vivo [3] and in vitro [4]. However, the PgR content of endometrial carcinoma varies directly to the degree of differentiation [5-7] and inversely with stage of the tumor [7]. Thus one would predict that MPA therapy would be less effective in advanced and poorly differentiated tumors. In addition, MPA has been shown to reduce PgR content of both normal [8] and malignant endometrial cells $[9,10]$, which could result in loss of hormone responsiveness. Tamoxifen (TAM), a nonsteroidal antiestrogen which is often used in breast cancer therapy, has also been used occasionally in the treatment of patients with advanced and recurrent endometrial carcinoma [11-16]. TAM is known to have some estrogenic effects at low concentration and one of these effects is induction of PgR both in normal [17] and malignant endometrium [18-20]. This property has focused interest on sequential or simultaneous use of TAM and MPA in the therapy of endometrial carcinoma. Zaino et al. [21] have shown greater regression of nude mouse tumors with sequential use of TAM and MPA than could be obtained with MPA alone. However, in the few clinical trials performed, simultaneous and sequential use of these agents has not been shown to increase the response rate over that achieved with MPA alone $[15,19,22]$.

Using cell cultures, we examined the direct growth inhibitory effect of these agents on endometrial carcinoma cells. This was accomplished by exposing logarithmically growing cell cultures to MPA and TAM. Simultaneous and sequential treatment of the cells with these agents was also studied. In addition to three long-established cell lines obtained from other laboratories, we studied a new cell line recently established in our laboratory. The in vitro sensitivity of this cell line was compared with the clinical response of its donor.

\section{MATERIALS AND METHODS}

Cell lines. The long-established endometrial cancer cell lines used in this study were obtained from the American Type Culture Collection (Rockville, MD). The HEC-1 cell line was established by Kuramoto et al. in 1972 from a moderately differentiated papillary endometrial adenocarcinoma [23]. KLE was established in 1984 by Richardson et al. from a poorly differentiated adenocarcinoma [24], and RL95-2 was established by Way et al. in 1983 from a moderately differentiated papillary adenocarcinoma [25]. The UM-EC-1 cell line was recently established in our laboratory from a poorly differentiated endometrial adenocarcinoma [26]. The MCF-7 breast cancer cell line established by Soule et al in 1973, from metastatic cells in pleural effusion [27], was obtained from Dr. C. McGrath of the Michigan Cancer Foundation. 
At least two studies of the estrogen receptor (ER) content of the HEC-1 cell line have been reported since the line was established. Shapira et al. [28] were not able to demonstrate specific estrogen binding in these cells, but Satyaswaroop et al. [29] found low levels of ER (10 fmole/mg protein) in HEC-1 cells. The KLE cell line was reported to contain varying amounts of cytosolic ER (25-300 fmole/mg protein) when it was tested at different passages during establishment of the cell line. Similarly, RL95-2 cells were reported to have both cytosolic ( $10.5 \mathrm{fmole} / \mathrm{mg}$ protein) and nuclear $(1020 \pm 230 \mathrm{fmole} / \mathrm{mg}$ DNA) ER when the cell line was first established in culture. The progesterone receptor content of these cell lines was not described in these reports. The MCF-7 cell line has been demonstrated to contain both ER and PgR, but subpopulations of this cell line lacking ER have also been reported [30,31].

The donor of UM-EC-1. The donor of UM-EC-1 cell line is a 66-year-old white female who underwent hysterectomy, bilateral salpingo-oophorectomy, lymph node biopsy, and liver cyst aspiration for endometrial carcinoma in June 1986. On histological evaluation the tumor revealed involvement of the cervix, the outer third of the myometrium, and the paraaortic lymph nodes. Cytologic evaluation of the fluid aspirated from a $2 \times 2-\mathrm{cm}$ cyst in the liver revealed cells consistent with primary tumor.

Steroid receptor assays. Steroid receptor content of the cell lines used in this study was tested in two different laboratories using the dextran-charcoal method as described previously [32]. Cells were grown to confluence in $75-\mathrm{cm}^{2}$ culture flasks in Dulbecco's minimum essential medium (DMEM) containing 1\% (v/v) nonessential amino acids, $2 \mathrm{~m} M$ L-glutamine, $100 \mathrm{u} / \mathrm{ml}$ penicillin, and $100 \mu \mathrm{g} / \mathrm{ml}$ streptomycin (DMEM +). DMEM + was supplemented with $15 \%$ fetal bovine serum (FBS) except as noted.

Three to five days before harvest, the cells were fed with DMEM + containing $5 \%$ dextran coated charcoal-treated FBS $\left(\mathrm{D}_{5}\right.$ medium). On the last day before harvest, the cultures were fed with Ham's F-12 medium. The cells were harvested by trypsinization and sedimented by centrifugation, and cell pellets of at least $500 \mathrm{mg}$ (wet wt) were immediately frozen and stored in liquid nitrogen until the assays were performed. The steroid receptor content of each of the long-established cell lines was assayed twice. UM-EC-1 cells were tested in six different assays using cells ranging from passage 4 to 35 . For one assay cells were grown in 480$\mathrm{cm}^{2}$ roller bottles by the method described above and in one experiment a nude mouse tumor induced by UM-EC-1 cells was tested.

Cell growth experiments. Cell growth experiments were performed as described previously [33]. Cells were cultured in 6-well plastic plates and allowed to grow for 3 days to reach the logarithmic growth phase. Thereafter, the medium and the drugs were replaced daily to ensure that nutrient depletion would not be a factor affecting cell growth and that fresh and effective drug was present each day during the entire experiment.

Drug preparation. Tamoxifen citrate was generously provided by Leiras-Medica Pharmaceuticals, Huhtamaki Oy, Turku, Finland. It was dissolved in $70 \%$ ethanol at 1000 times the highest final concentration used for experiments and stored as stock solutions at $-20^{\circ} \mathrm{C}$ until used. $17-\beta$-Estradiol $\left(\mathrm{E}^{2}\right)$ and $6-\alpha$-methyl-17 $-\alpha-$ 


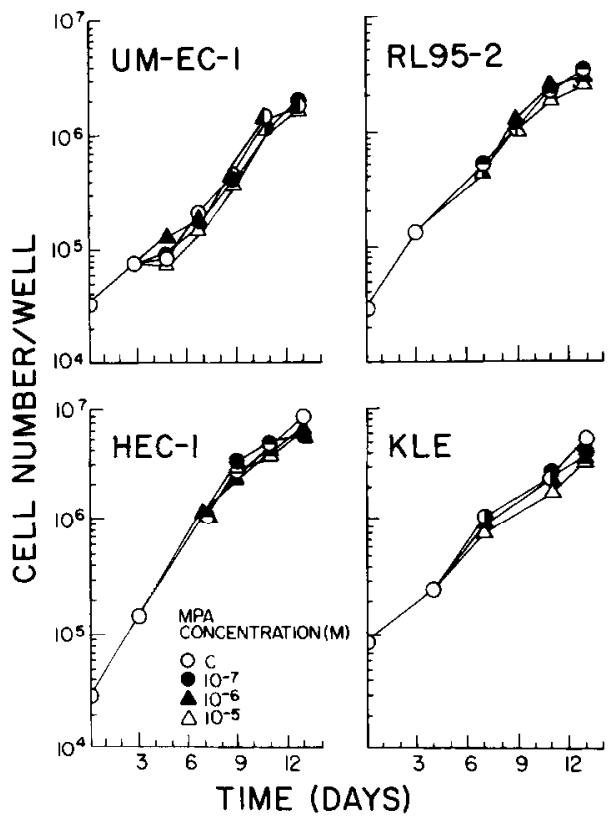

Fig. 1. Effect of medroxyprogesterone acetate (MPA) on the growth of endometrial carcinoma cells in culture. Cells were plated and allowed to grow for 3 to 4 days in $D_{5}$ medium and then were fed daily with $D_{5}$ medium containing the indicated concentrations of MPA. Three replicate wells were counted on each of the days indicated.

hydroxyprogesterone acetate (Sigma) were dissolved in absolute ethanol and diluted to the appropriate final concentration with culture medium. In drug-treated and control cultures the final concentration of ethanol was always less than $0.1 \%$. Ethanol at $0.1 \%$ or less does not effect growth rate, viability, or saturation density of the cultured cells [34].

\section{RESULTS}

\section{Steroid Receptor Content}

Steroid hormone receptors were not detected in any of the long-established endometrial carcinoma cell lines. In UM-EC-1 low amounts of ER $(6.5 \mathrm{fmole} / \mathrm{mg}$ protein) and $\mathrm{PgR}$ ( $22 \mathrm{fmole} / \mathrm{mg}$ protein) could be demonstrated only in one of the six assays. For this assay, cells from the fourth passage grown in roller bottles were used. In addition, the UM-EC-1 nude mouse tumor contained barely detectable levels of ER activity $(1.5 \mathrm{fmole} / \mathrm{mg}$ protein). No PgR binding was found in this specimen. As expected, MCF-7 cells were found to contain high but variable levels of both ER (105-454 fmole/mg protein) and PgR 21-120 fmole/mg protein) in repeated assays.

\section{Effects of MPA Alone on Cell Growth}

The effect of MPA on the growth of the endometrial carcinoma cell lines is presented in Fig. 1. Even with the highest MPA concentration tested $(10 \mu M)$, 


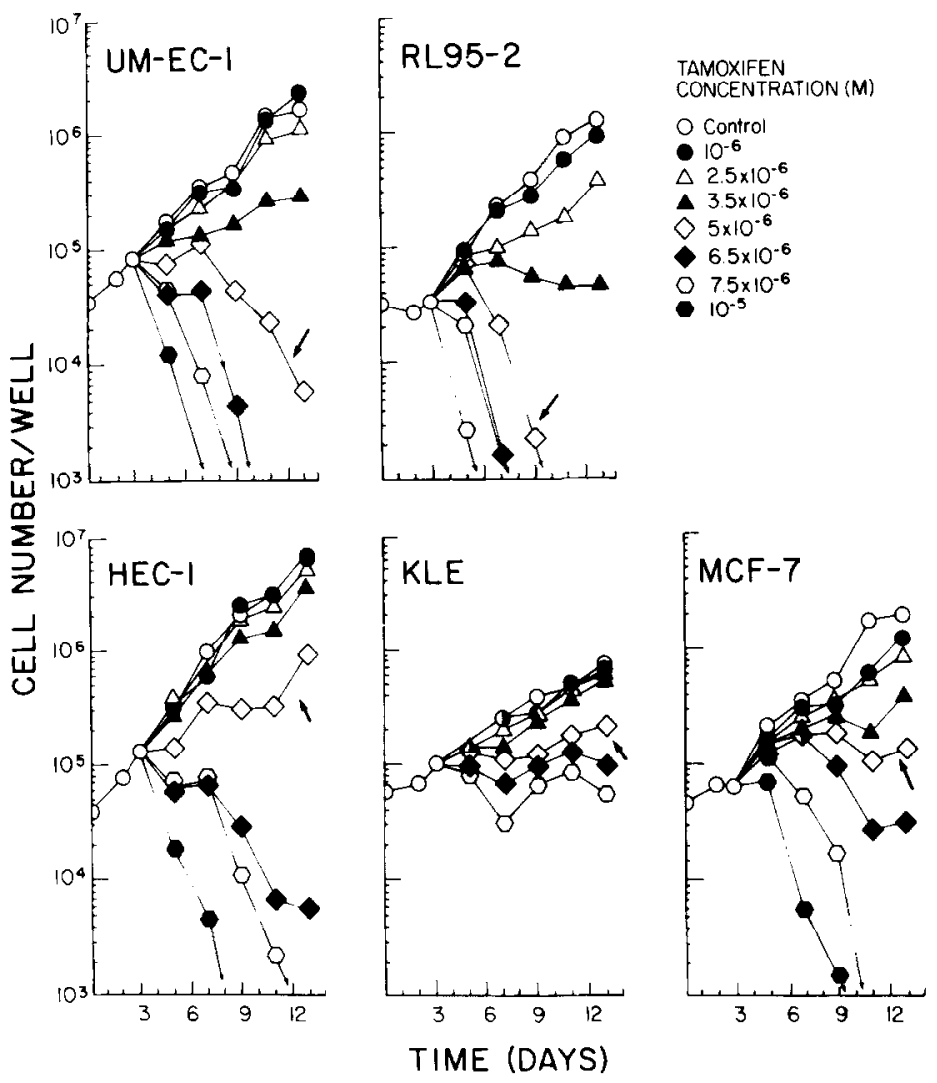

FIG. 2. Effects of daily feeding with tamoxifen on cell growth in endometrial carcinoma and MCF-7 cell lines. Cells were allowed to grow in $D_{5}$ medium for 3 days and then were fed daily with $D_{5}$ containing the indicated concentrations of tamoxifen. Replicate wells were counted on the days indicated. $5 \mu M$ TAM is indicated with an arrow.

only $27-30 \%$ reduction in cell number was achieved after 10 days of exposure to the drug. When the same concentration of MPA was present in the medium of $\mathrm{MCF}-7$ cells, the cell number was reduced by $68 \%$ compared to control (data not shown).

\section{Effects of TAM Alone on Cell Growth}

The results of a dose-response experiment showing the growth inhibitory effect of TAM on the four endometrial carcinoma cell lines and MCF-7 are presented in Fig. 2. Since $5 \mu M$ TAM was capable of inducing a cytostatic effect in MCF7 and also caused growth inhibition in all of the endometrial cancer cell lines, this concentration of TAM (marked with arrows in Fig. 2) was used in subsequent experiments. Ten days of feeding with $5 \mu M$ TAM produced a $93 \%$ reduction in cell number in MCF-7, an $83 \%$ reduction in HEC-1, and a $70 \%$ reduction in KLE cultures. In UM-EC-1 cultures a $99.7 \%$ reduction in cell growth was seen 


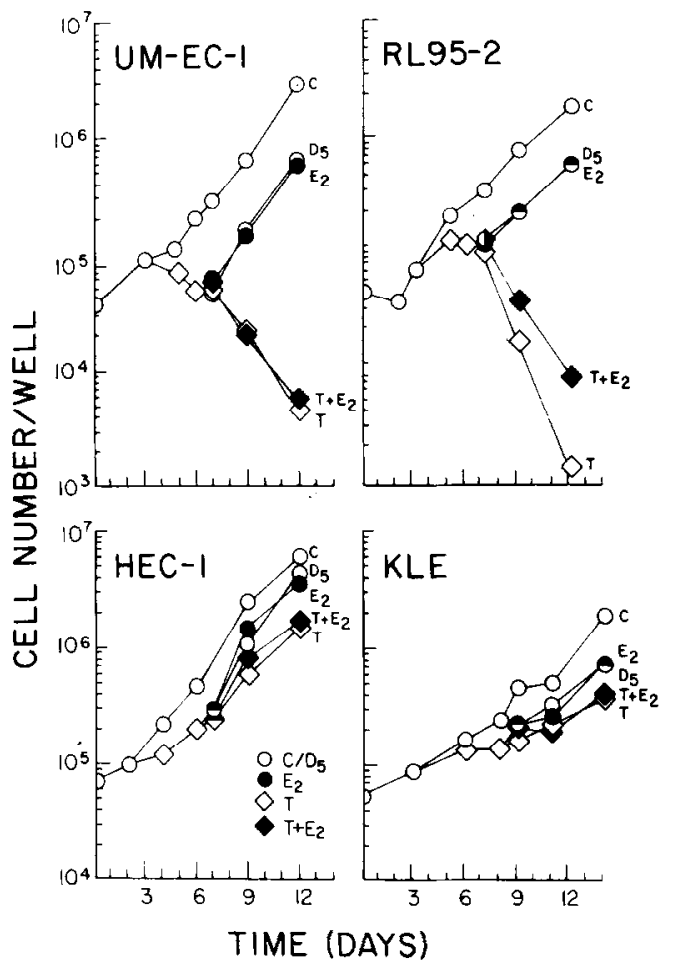

FIG. 3. Reversal of tamoxifen-induced growth inhibition in endometrial carcinoma cell lines is shown. Tamoxifen $(5 \mu M)$ was added to cultures starting from Day 2 or 3 . After 3 to 5 days of daily feeding with tamoxifen, the medium was removed from the wells and the cultures were fed with medium containing estradiol $\left(E_{2}\right), D_{5}$ medium $\left(D_{5}\right)$, tamoxifen plus estradiol $\left(T+E_{2}\right)$, or were continued in tamoxifen alone (T). Tamoxifen and estradiol were used in a ratio of 50:1. Control cultures grown in $D_{5}$ medium are indicated by the symbol $C$.

and no viable cells remained in RL95-2 cultures after 10 days of feeding with 5 $\mu M$ TAM.

\section{Reversibility of TAM-Induced Growth Inhibition}

In MCF-7 cultures TAM-induced growth inhibition has been shown to be partially reversed by simultaneous use of $E_{2}$, and $E_{2}$ has been shown to increase the rate of recovery from TAM blockade $[31,33,34]$. We examined whether $E_{2}$ would have the same effect in these endomentrial carcinoma cell line cultures. The results of this experiment are presented in Fig. 3.

After 3 to 5 days of feeding with $5 \mu M$ TAM, all cell lines resumed logarithmic growth when the drug was removed from the culture. The cells recovered equally well in the presence or absence of $0.1 \mu M \mathrm{E}_{2}\left(50: 1\right.$ ratio of TAM to $\left.\mathrm{E}_{2}\right)$. When TAM was replaced by medium containing both TAM and $\mathrm{E}_{2}$ (in a ratio of 50:1) in KLE, HEC-1, and UM-EC-1 cultures, the growth inhibitory effect remained the same as in cultures fed with TAM alone. In RL95-2 cultures, the growth inhibitory effect of TAM appeared to be partially blocked by $E_{2}$. However, in 


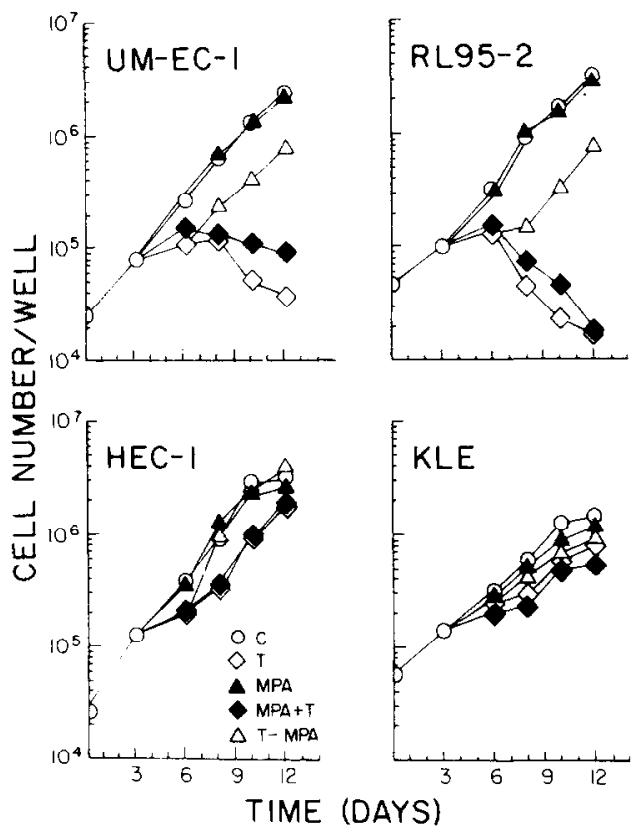

Fig. 4. Growth curves demonstrating the effect of $5 \mu M$ TAM and $5 \mu M$ MPA given sequentially or simultaneously on the growth of endometrial carcinoma cells in vitro. Cells were allowed to grown in $D_{5}$ medium for 3 days and then were fed daily with $D_{5}$ medium containing the indicated combinations of drugs. $\triangle$ indicates the use of TAM followed by MPA.

a subsequent experiment when these cells were fed with medium containing 5 $\mu M$ TAM and $1 \mu M \mathrm{E}_{2}$ (in a ratio of 5:1), reversal of TAM-induced growth inhibition could not be demonstrated.

\section{Simultaneous and Sequential Use of TAM and MPA}

To test the effects of the combination of TAM and MPA, these agents were administered simultaneously or sequentially to logarithmically growing cells. Results are presented in Fig. 4. In UM-EC-1 cultures, simultaneous exposure to $5 \mu M$ TAM and $5 \mu M$ MPA resulted in partial reversal of the TAM-induced growth inhibition, thus showing an antagonist effect of the two drugs. In RL95-2 and HEC-1 cultures, simultaneous use of these drugs had the same effect as TAM alone, whereas in KLE cultures a slight additive growth inhibitory effect was observed. All four endometrial carcinoma cell lines resumed logarithmic growth when medium containing TAM was replaced with medium containing MPA. Thus TAM did not increase the sensitivity of these cells to MPA. However, in KLE cultures recovery of logarithmic growth under these conditions was slower than that in the other endometrial carcinoma cultures.

\section{Effects of Postoperative Hormone Therapy in the Donor of UM-EC-I}

Postoperatively the donor of the UM-EC-1 cell line was given $160 \mathrm{mg}$ MPA/day for 6 weeks. During that time, vaginal cuff recurrence and pelvic node enlargement 
on CT scan were noted. The vaginal cuff recurrence was treated with a radioactive cesium implant. MPA was discontinued and the patient was given $40 \mathrm{mg}$ TAM per day. She began to show clinical improvement and resumed normal activities. She has had no evidence of disease for 6 months. A CT scan of the abdomen after 23 weeks of TAM treatment showed resolution of the pelvic nodal disease seen on the first CT scan. However, a mass was detected on this scan in the lower paraaortic region. The suboptimal quality of the first CT scan of the paraaortic region made it impossible to evaluate the tumor response in this area.

\section{DISCUSSION}

MPA has an established role in the therapy of advanced and metastatic endometrial carcinoma. The therapeutic value of TAM in these cases is not well established since in most studies it has been used as second-line chemotherapy for heavily pretreated patients and few controlled trials have been performed [11-16].

The mechanisms by which these hormonal agents exert growth inhibitory effects are under debate. The effects observed in vivo can be the result of either the direct effects of these agents on the tumor or the more indirect actions mediated through changes in the levels of circulating hormones. MPA is known to reduce circulating estrogen levels, to increase clearance of testosterone, and, consequently, to decrease conversion of androgens to estrogens [35]. MPA also has a high affinity for the PgR and it has been shown to reduce the PgR content of both normal [8] and malignant endometrial cells $[9,10]$. A good correlation has been shown between the PgR level in tumor tissue and the response to progestogens, with $82 \%$ responding when $\mathrm{PgR}$ is positive $[3,4]$ and only $11 \%$ when PgR is negative [3]. TAM has a complex mixture of estrogenic and antiestrogenic effects depending on the biological system, species, and concentration of the drug [21,36-38]. In vitro studies with breast cancer cell lines have shown that estrogen antagonism of TAM is mediated, at least in part, through estrogen receptor binding $[31,39,40]$, but there is also evidence of a specific antiestrogen binding site (AEBS) that is distinct from the ER [40-42].

The use of TAM as a chemotherapeutic agent in the treatment of endometrial adenocarcinoma has given mixed results. In a pilot study, Swenerton et al. [11] reported a response to TAM in 4 of 7 patients studied. Similarly, Bonte et al. achieved complete regression in 2 and partial regression in 7 of 17 patients treated with TAM as a second-line therapy [12]. However, in a study performed by the Gynecologic Oncology Group, no tumor regression occurred in 17 patients with endometrial adenocarcinoma. Nevertheless, 11 patients had stable disease for 8-48 weeks, although the remaining 6 patients showed progression of the disease. In the same study, of the 5 patients with adenosquamous carcinoma of the endometrium, 2 had stable disease for 4 and 16 weeks, and 3 experienced progression [14]. Unfortunately it is not possible to judge the therapeutic value of TAM from these studies in which the drug was used as palliative treatment. In spite of this, the rather striking clinical responses observed in several patients stand out.

We studied the direct growth inhibitory effects of MPA and TAM on four endometrial carcinoma cell lines. When the cells were exposed to 0.1 and $1 \mu M$ 
MPA, no growth inhibitory effect was seen and at $10 \mu M$ MPA concentration only $30 \%$ growth inhibition was observed. Our findings are in accordance with the results of Satyaswaroop et al. [43] and Ishiwata et al. [44], who have shown MPA-induced growth inhibition in endometrial carcinoma cell cultures only at very high concentrations. On the other hand, it is to be noted that consistent detectable PgR activity was not found in any of these endometrial carcinoma cell lines. MCF-7 cells which have more stable expression of PgR activity were inhibited by $10 \mu M$ MPA.

The TAM concentrations used in this study are of the same magnitude as those used in previous studies dealing with TAM-induced growth inhibition in breast cancer cell cultures $[31,39,40,42]$. In all cell lines we found clear, dosedependent TAM-induced effects on cell growth and viability which varied from $70 \%$ growth inhibition to complete cell kill after 10 days of feeding with $5 \mu M$ TAM. When a $1 \mu M$ TAM concentration was used, no growth inhibition was observed, which is in accordance with the results of Holinka $e t$ al. who used 1 $\mu M$ TAM in Ishikawa cell cultures [45].

In in vitro studies with breast cancer cell lines, three distinct effects of TAM have been demonstrated. These include both estrogen-reversible and estrogenirreversible growth inhibitory effects and what has been termed the direct cytotoxic effect of TAM [40,42]. TAM-inhibited MCF-7 cultures have been shown to recover faster in the presence of $E_{2}$ than in medium alone $[33,34,46]$. Furthermore, simultaneous use of TAM and $E_{2}$ results in partial reversal of growth inhibition $[31,33,34,42,46]$. In the experiments reported herein using endometrial carcinoma cell lines, no competitive effects of TAM and $\mathrm{E}_{2}$ were noted. The endometrial carcinoma cells recovered from TAM-induced growth inhibition equally well in both the presence and absence of $E_{2}$, and simultaneous exposure of the cells to TAM and $E_{2}$ did not reduce the growth inhibitory effect of the TAM. These results are very similar to those we obtained previously with cervical carcinoma cells [33] and with some, but not all, squamous cell carcinomas of the head and neck region $[34,46]$. In those experiments, TAM was shown to have a dosedependent, estrogen-irreversible growth inhibitory effect on certain cell lines. Taken together, our present findings and some of our earlier results indicate that in some cancer cell types TAM has a potent growth-regulating effect that is independent of the action mediated through the ER.

Progestins are known to decrease PgR content of cells which may reduce the drug's inhibitory effect and allow primarily responsive tumors to escape therapy $[9,10]$. In contrast, in both clinical $[18-20]$ and nude mouse $[20,37]$ studies TAM has been shown to increase the PgR content of endometrial carcinoma tissue. However, in clinical trials sequential or simultaneous administration of MPA and TAM has not been superior to that of MPA alone [15,19,22].

We were not able to increase the sensitivity of endometrial carcinoma cell lines to MPA by either simultaneous or sequential combinations of TAM and MPA in three of four endometrial carcinoma cell cultures. KLE cells did appear to have a slight increase in growth inhibition with simultaneous administration of the drugs. This was the only line which retained susceptibility to MPA alone, a finding that is compatible with the two agents working by different mechanisms. 
In contrast, in UM-EC-1 cultures simultaneous use of these drugs resulted in partial reversal of the TAM-induced growth inhibition. The mechanism responsible for this finding remains unclear, but could be the result of competition for a single receptor if both drugs do not have the same effect on that receptor.

In the case of UM-EC-1 we had an opportunity to compare the clinical response of the patient with the in vitro response achieved with MPA and TAM. We were not able to demonstrate significant growth inhibition in UM-EC-1 cultures even with $10 \mu M$ MPA and correspondingly the disease progressed in the patient during 6 weeks of postoperative therapy with MPA. In contrast, UM-EC-1 was very sensitive to $5 \mu M$ TAM in vitro and in the patient at least a partial regression of lymphatic disease occurred with moderately high-dose TAM treatment. Thus there was a good correlation between the in vitro and in vivo responses.

Our data from this study and from our previous studies with cervical carcinoma and head and neck carcinoma cultures indicate that the in vitro growth inhibitory effect of TAM can be demonstrated in ER-negative cell lines and appears to be mediated through a mechanism different from blockade of high-affinity ER. Furthermore, in this study TAM has been shown to have potent growth inhibitory effects on progesterone receptor-negative and therefore MPA-resistant endometrial carcinoma cells. These findings are of special importance since patients who are most likely to need adjuvant therapy for advanced or recurrent endometrial carcinoma are those with ER- and PgR-negative tumors. Randomized controlled studies of the use of high-dose TAM as a first-line chemotherapeutic agent in poorly differentiated endometrial carcinoma should be considered.

Note added in proof.

Since the completion of this manuscript a new cell line, UM-EC-2, has been established from another patient with MPA-resistant, advanced, poorly differentiated endometrial carcinoma. UMEC-2, like the cell lines described in this paper, is very sensitive to growth regulation by tamoxifen.

\section{REFERENCES}

1. Briggs, M. H., Caldwell, A. B. S., and Pitchford, A. G. The treatment of cancer by progestogens, Hosp. Med. 2, 63-72 (1967).

2. Kohorn, E. I. Gestagens and endometrial carcinoma, Gynecol. Oncol. 4, 398-411 (1976).

3. Quinn, M. A., Cauchi, M., and Fortune, D. Endometrial carcinoma: Steroid receptors and response to medroxyprogesterone acetate, Gynecol. Oncol. 21, 314-319 (1985).

4. Gr̈onroos, M., Paul, R., Kangas. L.. Erkkola. R.. Mäenpää. and Grenman. S. Steroid receptors and response of endometrial cancer to hormones, Ann. Chir. Gynecol. 76 (Suppl. 202) 76-79 (1987).

5. Creasman, W. T., McCarty, K. S., Barton, T. K., and McCarty, K. S., Jr. Clinical correlates of estrogen- and progesterone-binding proteins in human endometrial adenocarcinoma, Obstet. Gynecol. 55, 363-370 (1982).

6. Ehrlich, C. E., Young, P. C. M., and Cleary, R. E. Cytoplasmic progesterone and estradiol receptors in normal, hyperplastic and carcinomatous endometria: Therapeutic implications, Amer. J. Obstet. Gynecol. 141, 539 (1981).

7. Kauppila, A. J. I., Isotalo, H. E., Kivinen, S. T., and Vihko, R. K. Prediction of clinical outcome with estrugen and progestin receptor concentrations and their relationship to clinical and histopathological variables in endometrial cancer, Cancer Res. 46, 5380-5384 (1986).

8. Neumannova, M., Kauppila, A., Kivinen, S., and Vihko, R. Short-term effects of tamoxifen, medroxprogesterone acetate and their combination on receptor kinetics and 17- $\beta$-hydroxysteroid dehydrogenase in human endometrium, Obstet. Gynecol. 66, 695-700 (1985).

9. Janne, O., Kauppila, A., Kontula, K., Syrjala, P., and Vihko. R. Female sex steroid receptors in normal, hyperplastic and carcinomatous endometrium: The relationship to serum steroid 
hormones and gonadotropins and changes during medroxprogesterone acetate administration, Int. J. Cancer 24, 545-554 (1979).

10. Biondani, P., Costanzo, C., Gerruti, G., and Ros, A. Endometrial cancer: Steroid receptors and medroxyprogesterone acetate treatment, in Steroids and endometrial cancer (V. M. Jasonni, et al., Eds.), Raven Press, New York, pp. 209-210 (1983).

11. Swenerton, K. D., Shaw, D., White, G. W., and Boyes, D. A. Treatment of advanced endometrial carcinoma with tamoxifen, N. Engl. J. Med. 301, 105 (1979).

12. Bonte, J., Ide, P., Billiet, G., and Wynants, P. Tamoxifen as a possible chemotherapeutic agent in endometrial adenocarcinoma, Gynecol. Oncol. 11, 140-161 (1981).

13. Kauppila, A., and Vihko, R. Case report: Endometrial carcinoma insensitive to progestin and cytotoxic chemotherapy may respond to tamoxifen, Acta Obstet. Gynecol. Scand. 60, 589590 (1981).

14. Slavik, M., Petty, W. M., Blessing, J. A., Creasman, W. T., and Homesley, H. D. Phase II clinical study of tamoxifen in advanced endometrial adenocarcinoma: A gynecologic oncology group study, Cancer Treat. Rep. 68, 799 811 (1984).

15. Swenerton, K. D., Chrumka, K., Paterson, A. H. G., and Jackson, G. C. Efficacy of tamoxifen in endometrial cancer, in Progress in cancer research and therapy (F. Bresciana, et al., Eds.), Raven Press, New York, Vol. 31, pp. 417-424 (1984).

16. Edmondson, J. H., Krook, J. E., Hilton, J. F. et al. Ineffectiveness of tamoxifen in advanced endometrial carcinoma after failure of progestin treatment, Cancer Treat. Rep. 70, 1019-1020 (1986).

17. Isomaa, V., Isotalo, H., Orava, M., and Janne, O. Regulation of cytosol and nuclear progesterone receptors in rabbit uterus by estrogen, antiestrogen and progesterone administration, Biochim. Biophys. Acta 585, 24-33 (1979).

18. Mortel, R., Levy, C., Wolff, J.-P., Nicolas, J.-C., Robel, P., and Baulieu, E.-E. Female sex steroid receptors in postmenopausal endometrial carcinoma and biochemical response to an antiestrogen, Cancer Res. 41, 1140-1147 (1981).

19. Carlson, J. A., Allegra, J. C., Day, T. G., and Wittliff, J. I. Tamoxifen and endometrial carcinoma: Alterations in estrogen and progesterone receptors in untreated patients and combination hormonal therapy in advanced neoplasia, Amer. J. Obstet. Gynecol. 149, 149-153 (1984).

20. Schwartz, P. E., MacLusky, N., Naftolin, F., Phil, D., and Eisenfeld, A. Tamoxifen-induced increase in cytosol progestin receptor levels in a case of metastatic endometrial cancer, Gynecol. Oncol. 16, 41-48 (1983).

21. Zaino, R. J., Satyaswaroop, P. G., and Mortel, R. Hormonal therapy of human endometrial adenocarcinoma in a nude mouse, Cancer Res. 45, 539-541 (1985).

22. Bonte, J. Hormone dependency and hormone responsiveness of endometrial adenocarcinoma to estrogens, progestogens and antiestrogens, in Role of medroxyprogesterone in endocrinerelated tumors (L. Campio et al. Eds.), New York, Raven Press, Vol. II, pp. 141-156 (1983).

23. Kuramoto, H., Tamura, S., and Notake, Y. Establishment of a cell line of human endometrial adenocarcinoma in vitro, Amer. J. Obstet. Gynecol. 114, 1012-1019 (1972).

24. Richardson, G. S., Dickersin, G. R., Atkins, L., MacLaughlin, D. T., Raam, S., Merk, L., and Bradley, F. M. KLE: A cell line with defective estrogen receptor derived from undifferentiated endometrial cancer, Gynecol. Oncol. 17, 213-230 (1984).

25. Way, D. L., Grosso, S., Davis, J. R., Surwit, E. A., and Christian, C. D. Characterization of a new human endometrial carcinoma (RL95-2) established in tissue culture, In Vitro 19, 147158 (1983).

26. Grenman, S., Van Dyke, D. L., Worsham, M. J., del Rosario, F., Roberts, J. A., McClatchey, K. D., Schwartz, D. R., and Carey, T. E. UM-EC-1, a new hypodiploid human cell line derived from a poorly differentiated endometrial cancer, Cancer Res. In press 1988.

27. Soule, H. D., Vasquez, J., Long, A., Alberts, B. M. A human cell line from a pleural effusion derived from a breast carcinoma, J. Natl. Cancer Inst. 51, 1409-1416 (1973).

28. Shapira, S. S., van der Schouw, M., and Hagerman. D. D. Failure of estrogen and progesterone to affect protein synthesis by an established endometrial cell line, Amer.J. Obstet. Gynecol. 1, 570-571 (1975). 
29. Satyaswaroop, P. G., Fleming, H., Bressler, R. S., and Gurpide, E. Human endometrial cancer cell cultures for hormonal studies, Cancer Res. 38, 4367-4375 (1976).

30. Horwitz, K. B., Costlow, M. E., and McGuire, W. L. MCF-7, a human breast cancer cell line with estrogen, androgen, progesterone and glucocorticoid receptors, Steroids 26, 785-794 (1975).

31. Reddel, R. R., Murphy, L. C., Hall, R. E., and Sutherland, R. L. Differential sensitivity of human breast cancer cell lines to the growth inhibitory effects of tamoxifen, Cancer Res. 45, 1525-1531 (1985).

32. Virolainen, E., Vanharanta, R., and Carey, T. E. Steroid hormone receptors in human squamous carcinoma cell lines, Int. J. Cancer 33, 19-25 (1984).

33. Grenman, S., Shapira, A., and Carey, T. E. In vitro response of cervical cancer cell lines CaSki, HeLa, and ME-180 to the antiestrogen tamoxifen, Gynecol. Oncol. 30, 228-238 (1988).

34. Shapira, A., Virolainen, E., Jameson, J. J., Ossakow, S. J., and Carey, T. E. Growth inhibition of laryngeal UM-SCC cell lines by tamoxifen, Arch. Otolaryngol Head Neck Surg. 112, 11511158 (1986).

35. Pannuti, F., Martoni, A., Camaggi, C. M., et al. in Proceedings of the International Symposium on Medroxyprogesterone Acetate (F. Cavelli, et al. Eds.), Excerpta Medica, Amsterdam, pp. 5-43 (1982).

36. Martin, L., and Middleton, E. Prolonged oestrogenic and mitogenic activity of tamoxifen in the ovarectomized mouse, J. Endocrinol. 78, 125-129 (1978).

37. Satyaswaroop, P. G., Zaino, R. J. and Mortel, R. Estrogen-like effects of tamoxifen on human endometrial carcinoma transplanted into nude mice, Cancer Res. 44, 4006-4010 (1984).

38. Jordan, V. C., Fritz, N. F., and Torney, D. C. Endocrine effects of adjuvant chemotherapy and long-term tamoxifen administration on node-positive patients with breast cancer, Cancer Res. 47, 624-630 (1987).

39. Coesy, E., Borgna, J.-L., and Rochefort, H. Tamoxifen and metabolites in MCF-7 cells: Correlation between binding to estrogen receptor and inhibition of cell growth, Cancer Res. 42, 317-323 (1982).

40. Miller, M. A., and Katzenellenbogen, B. S. Characterization and quantitation of antiestrogen binding sites in estrogen receptor-positive and negative human breast cancer cell lines, Cancer Res. 43, $3094-3100$ (1983).

41. Sutherland, R. L., Murphy, L. C., San Foo, M., Green, M. D., Whybourne, A. M. High affinity antiestrogen binding site distinct from the estrogen receptor, Nature (London) 288, 273-275 (1980).

42. Sutherland, R. L., Murphy, L. C., Hall, R. E., Reddel, R. R., Watts, C. K. W., and Taylor, I. W. Effects of antioestrogens on human breast cancer cells in vitro: Interactions with high affinity intracellular binding sites and effects on cell proliferation kinetics, in Progress in cancer research and therapy (F. Bresciani, et al. Eds.), Raven Press, New York, Vol. 31, pp. 193212 (1984).

43. Satyaswaroop, P. G., Frost, A., and Gurpide, E. Metabolism and effects of progesterone in the human endometrial adenocarcinoma cell line HEC-1, Steroids, 35, 21-37 (1980).

44. Ishiwata, I., Nozawa, S., and Okumura, H. Effects of 17- $\beta$-estradiol and progesterone on growth and morphology of human endometrial carcinoma cells in vitro, Cancer Res. 37, 4246-4249 (1977).

45. Holinka, C. F., Hata, H., Kuramoto, H., and Gurpide, E. Responses to estradiol in a human endometrial adenocarcinoma cell line (Ishikawa), J. Steroid Biochem. 24, 85-89 (1986).

46. Grenman, R., Virolainen, E., Shapira, A., and Carey, T. E. In vitro effects of tamoxifen on UM-SCC head and neck cancer cell lines: Correlation with the estrogen and progesterone receptor content, Int. J. Cancer 39, 77-81 (1987). 